\title{
Nutrição e produtividade da cultura do milho em sistemas de culturas e fontes de adubação
}

\author{
Mônica Sarolli Silva de Mendonça Costa ${ }^{1 *}$, Fábio Steiner ${ }^{2}$, Luiz Antonio de Mendonça Costa ${ }^{3}$, \\ Gustavo Castoldi', Laércio Augusto Pivetta ${ }^{2}$
}

\section{RESUMO}

A utilização de esterco animal na agricultura, aliada ao cultivo de plantas de cobertura, pode conferir sustentabilidade ao sistema agrícola. Com o objetivo de avaliar o efeito de dois sistemas de culturas e de três fontes de nutrientes, na cultura do milho, conduziu-se um experimento, em Latossolo Vermelho, no município de Marechal Cândido Rondon (PR). O delineamento experimental utilizado foi de blocos casualizados, com quatro repetições, e, os tratamentos, dispostos em esquema fatorial 2 × 3 , compostos por dois sistemas de culturas (sucessão trigo/milho e consórcio aveia+ervilhaca+nabo/milho) e três fontes de nutrientes (mineral, orgânica e organomineral). Em junho de 2006, implantou-se a cultura do trigo e o consórcio de plantas de cobertura. Em outubro de 2006, semeou-se milho em ambos os sistemas. As adubações orgânica e organomineral consistiram na aplicação de dejetos de suínos, unicamente, e combinada com fertilizante mineral, respectivamente. O consórcio de aveia preta, ervilhaca peluda e nabo forrageiro mostrou-se capaz de fornecer a quantidade adequada de biomassa, viabilizando o seu cultivo para produção de cobertura vegetal ao solo, durante o inverno. O cultivo de milho em sucessão ao trigo proporcionou a maior absorção de $\mathrm{N}$ e K e a maior produtividade. A adubação mineral proporcionou maior absorção de $\mathrm{N}$ e maior produtividade de milho, em comparação com as adubações orgânica e organomineral com dejetos de suínos.

Palavras-chave: Zea mays, sucessão de culturas, adubação orgânica.

\section{ABSTRACT}

\section{Nutrition and yield of corn under different cropping systems and nutrient sources}

The use of animal manure combined with cover crops can provide sustainability to agricultural systems. Aiming to evaluate the effect of two farming systems and nutrient sources on the corn crop, an experiment was conducted on an Oxisol, in the municipality of Marechal Candido Rondon, Paraná State, Brazil . The experiment was arranged in a randomized block design with treatments in a factorial scheme 2 x 3, consisting of two crop systems (succession wheat/ corn and intercropping oat+vetch+turnip/corn) and three nutrient sources (mineral, organic and organic-mineral), with four replications. In June 2006, the wheat crop and the intercropping of cover crops were established. In October 2006, the corn was sowed on the two systems. Organic and organic-mineral fertilizations consisted of application of pig manure alone and combined with mineral fertilizer, respectively. Intercropping of oat, hairy vetch and wild radish produced adequate amount of biomass, showing its viability for providing soil cover during winter. Corn grown in rotation with wheat yielded the highest uptake of $\mathrm{N}$ and $\mathrm{K}$ and highest yield. Mineral fertilization gave higher $\mathrm{N}$ uptake and corn yield compared with the organic fertilizer and organic-mineral fertilizer based on pig manure.

Key Words: Zea mays L., succession of crops, organic fertilizer.

\footnotetext{
Recebido para publicação em fevereiro de 2010 e aprovado em março de 2011

Engenheira Agrícola, Doutora. Universidade Estadual do Oeste do Paraná - UNIOESTE. Rua Universitária, 2069, 85819-110, Cascavel, Paraná, Brasil, monicas@unioeste.br. ${ }^{2}$ Engenheiro-Agrônomo. Doutorando em Agronomia/Agricultura, Faculdade de Ciências Agronômicas - UNESP, Fazenda Experimental Lageado, Rua José Barbosa de Barros, 1780, 18610-370, Botucatu, São Paulo,Brasil. fsteiner@fca.unesp.br, castoldi@fca.unesp.br, laerciopivetta@fca.unesp.br

Engenheiro-Agrônomo, Doutor. UNIOESTE, Rua Universitária, 2069, 85819-110, Cascavel, Paraná, Brasil, Imendo@ig.com.br.
} 


\section{INTRODUÇÃO}

O sistema plantio direto (SPD) é uma realidade na agricultura brasileira, trazendo grandes benefícios quanto à conservação e melhoria das qualidades físicas, químicas e biológicas do solo. Entretanto, para assegurar sua sustentabilidade, é fundamental um sistema de rotação e sucessão de culturas diversificado, que produza adequada quantidade de resíduos vegetais na superfície do solo, durante todo o ano (Ceretta et al., 2002).

O Estado do Paraná cultiva mais de 6 milhões de hectares na safra de verão. No inverno, apenas uma pequena área é cultivada, ficando o restante exposto à ação da erosão, lixiviação de nutrientes, infestação de plantas daninhas e riscos de degradação ambiental (Calegari, 2006). Entretanto, nos últimos anos essa realidade vem-se alterando e o cultivo de plantas de cobertura tem-se mostrado eficiente no controle da erosão, proporcionando cobertura e proteção ao solo, reciclagem de nutrientes, aumento do potencial produtivo e diminuição dos custos de produção.

Além da possibilidade de melhoria e, ou, conservação do solo e da matéria orgânica, as plantas de cobertura promovem consideráveis aumentos de rendimento das culturas subsequentes. Apresentam também significativa viabilidade econômica, por permitirem melhor aproveitamento e redução da adubação mineral nas culturas subsequentes, com o decorrer dos anos, num adequado sistema de cultivo e rotação de culturas.

Na região oeste do Estado do Paraná, a existência de considerável quantidade de esterco animal possibilita a adubação orgânica, ou, mesmo, a associação desta com a adubação mineral. A utilização de resíduos de animais, associada ao uso de plantas de cobertura, promoveria uma sincronização entre a mineralização e a demanda de nutrientes pelas culturas, contribuindo, assim, para a melhoria da produtividade do sistema. Entretanto, é necessário conhecer as características químicas dos resíduos, bem como seus efeitos sobre o desenvolvimento das plantas, além de possíveis impactos negativos sobre o meio ambiente.

Até o momento, as informações disponíveis na literatura, quanto ao uso associado de adubação orgânica com fertilizantes minerais, são incipientes e escassas. Trabalhando em um Argissolo Vermelho-Amarelo, Gomes et al. (2005) verificaram que a associação de composto orgânico e adubo químico não influenciou, significativamente, o rendimento da cultura de milho. Os autores ainda constataram que a produtividade do milho, ante a aplicação de $40 \mathrm{~m}^{3}$ ha${ }^{1}$ de composto orgânico, assemelhou-se àquela obtida com a utilização de $500 \mathrm{~kg} \mathrm{ha}^{-1}$ da formulação 04-14-08.

Assim, este trabalho teve como objetivo avaliar o efeito do consórcio entre aveia+ervilhaca+nabo, como plan- tas de cobertura no inverno, e do cultivo de trigo na nutrição e produtividade do milho em sucessão, com aplicação de três fontes de nutrientes.

\section{MATERIAL E MÉTODOS}

O experimento foi conduzido em sistema de semeadura direta, na Estação Experimental Agronômica da Universidade Estadual do Oeste do Paraná - UNIOESTE, em Marechal Cândido Rondon - PR (latitude: $24^{\circ} 31^{\prime}$ S, longitude: $54^{\circ} 01^{\prime} \mathrm{W}$ e altitude: $420 \mathrm{~m}$ ).

O clima da região, segundo classificação de Köppen, é do tipo $\mathrm{Cfa}$, com verão quente (temperatura média superior a $22^{\circ} \mathrm{C}$ ) e tendência de concentração das chuvas, e inverno com geadas pouco frequentes (temperatura média inferior a $18^{\circ} \mathrm{C}$ ), sem estação definida, apresentando precipitação média anual de $1.500 \mathrm{~mm}$. Os dados climáticos durante a realização do experimento encontram-se na Figura 1.

O solo é classificado como Latossolo Vermelho eutroférrico típico (EMBRAPA, 2006), profundo, bem drenado e com textura muito argilosa $\left(640 \mathrm{~g} \mathrm{~kg}^{-1}\right.$ de argila, 260 $\mathrm{g} \mathrm{kg}^{-1}$ de silte e $100 \mathrm{~g} \mathrm{~kg}^{-1}$ de areia). A análise química do solo, efetuada antes da instalação do experimento, apresentou os seguintes resultados: $\mathrm{pH} \mathrm{em} \mathrm{CaCl}_{2}$ de 4,7; $27 \mathrm{~g}$ $\mathrm{dm}^{-3}$ de matéria orgânica; $22 \mathrm{mg} \mathrm{dm}^{-3}$ de P (Mehlich-1); $2,85 \mathrm{cmol}_{\mathrm{c}} \mathrm{dm}^{-3} \mathrm{de} \mathrm{Ca} ; 1,50 \mathrm{cmol}_{\mathrm{c}} \mathrm{dm}^{-3} \mathrm{de} \mathrm{Mg} ; 0,30 \mathrm{cmol}_{\mathrm{c}}$ $\mathrm{dm}^{-3}$ de K; CTC pH 7,0 de 11,0 $\mathrm{cmol}_{\mathrm{c}} \mathrm{dm}^{-3}$ e saturação por bases de $47 \%$. Anteriormente, a área vinha sendo cultivada, em sistema de semeadura direta por seis anos, com trigo (Triticum aestivum L.) no outono/inverno e soja (Glycine max L. (Merr.)) ou milho (Zea mays L.), no período de primavera/verão.

O experimento constou de dois sistemas de culturas e três fontes de nutrientes, dispostos segundo um delineamento de blocos completos ao acaso, com quatro repetições. Ambos os sistemas foram instalados em junho de 2006, a partir da semeadura das culturas de inverno, sendo compostos pelo consórcio de aveia preta + ervilhaca peluda + nabo forrageiro/milho (sistema em sucessão com plantas de cobertura) e trigo/milho (sistema em sucessão ao trigo). Cada unidade experimental foi constituída por $12,0 \mathrm{~m}$ de comprimento por 7,4 $\mathrm{m}$ de largura $\left(88,8 \mathrm{~m}^{2}\right)$.

As plantas de cobertura foram semeadas mecanicamente, em linhas espaçadas de $0,17 \mathrm{~m}$, na proporção de 50,20 e $10 \mathrm{~kg} \mathrm{ha}^{-1}$ de sementes, respectivamente, de aveia, ervilhaca e nabo. O consórcio de plantas de cobertura não foi adubado, para que não houvesse interferência de adubação em nenhuma parcela e, se pudesse, assim, verificar apenas o efeito dos resíduos vegetais no sistema de culturas em sucessão proposto. O trigo cultivar IPR 85 foi semeado em linhas espaçadas de 0,17 m entre si, utilizando-se 350 sementes $\mathrm{m}^{-2}$. 


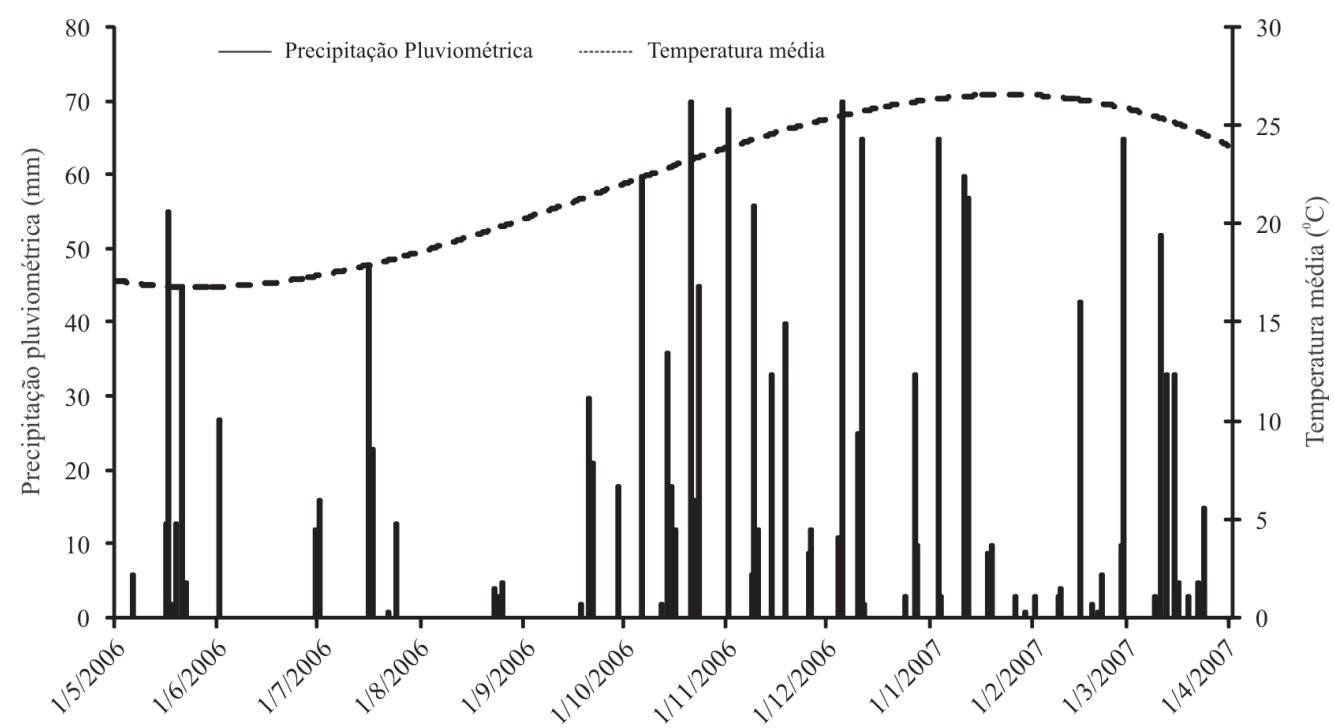

Figura 1. Precipitação pluviométrica $(\mathrm{mm})$ e temperatura média mensal $\left({ }^{\circ} \mathrm{C}\right)$ durante o período de maio/2006 a março/2007. Fonte: Estação Meteorológica do Núcleo de Estações Experimentais da UNIOESTE. Marechal Cândido Rondon/PR.

As fontes de nutrientes constaram da aplicação de fertilizante mineral (adubação mineral), dejetos de suínos (adubação orgânica) e dejetos de suínos + fertilizante mineral (adubação organomineral).

A adubação mineral do trigo foi realizada com a aplicação de $50 \mathrm{~kg} \mathrm{ha}^{-1}$ de N, $20 \mathrm{~kg} \mathrm{ha}^{-1}$ de $\mathrm{P}_{2} \mathrm{O}_{5}$ e $30 \mathrm{~kg} \mathrm{ha}^{-1}$ de $\mathrm{K}_{2} \mathrm{O}$, na forma de ureia, superfosfato triplo (SFT) e cloreto de potássio $(\mathrm{KCl})$, respectivamente. A adubação nitrogenada foi dividida em duas aplicações, $25 \mathrm{~kg} \mathrm{ha}^{-1} \mathrm{de}$ $\mathrm{N}$ na emergência das plantas e $25 \mathrm{~kg} \mathrm{ha}^{-1}$ de $\mathrm{N}$ no perfilhamento, na forma de ureia. A adubação orgânica foi realizada com a aplicação de dejeto suíno na superfície do solo, um dia antes da semeadura do trigo, na quantidade de $25 \mathrm{~m}^{3} \mathrm{ha}^{-1}$, de modo a fornecer 50,15 e $18 \mathrm{~kg} \mathrm{ha}^{-1} \mathrm{de} \mathrm{N}$, $\mathrm{P}_{2} \mathrm{O}_{5}$ e $\mathrm{K}_{2} \mathrm{O}$. Para a adubação organomineral, o dejeto suíno foi aplicado na superfície um dia antes da semeadura do trigo, para suprir a necessidade de $\mathrm{N}$, na quantidade de $25 \mathrm{~m}^{3} \mathrm{ha}^{-1}$, e foram distribuídos, a lanço, $5 \mathrm{~kg} \mathrm{ha}^{-1} \mathrm{de}$ $\mathrm{P}_{2} \mathrm{O}_{5}$ e $12 \mathrm{~kg} \mathrm{ha}^{-1}$ de $\mathrm{K}_{2} \mathrm{O}$, como SFT e $\mathrm{KCl}$, respectivamente, de modo a manter a mesma quantidade de $\mathrm{N}, \mathrm{P}_{2} \mathrm{O}_{5}$ e $\mathrm{K}_{2} \mathrm{O}$ da adubação mineral. $\mathrm{O}$ dejeto suíno foi coletado em lagoa de estabilização e apresentou as seguintes características físico-químicas: $2,4 \%$ de matéria seca; $2,00 \mathrm{~kg} \mathrm{~m}^{-3}$ de $\mathrm{N} ; 0,60 \mathrm{~kg} \mathrm{~m}^{-3} \mathrm{de}_{2} \mathrm{O}_{5} ; 0,72 \mathrm{~kg} \mathrm{~m}^{-3}$ de $\mathrm{K}_{2} \mathrm{O} ; 41,0 \mathrm{~kg} \mathrm{~m}^{-3}$ de $\mathrm{Ca}$ e $5,9 \mathrm{~kg} \mathrm{~m}^{-3}$ de $\mathrm{Mg}$.

No florescimento das espécies, ocorrido no final do mês de agosto, realizou-se o manejo das plantas de cobertura, utilizando-se o rolo-faca, de forma a manter os resíduos vegetais na superfície do solo. Após o manejo das plantas de cobertura, determinou-se sua produção de matéria seca, coletando-se, aleatoriamente, duas amostras de $0,25 \mathrm{~m}^{2}$ por parcela, com o auxílio de um quadro de $0,5 \times 0,5 \mathrm{~m}$. As amostras foram secas em estufa de circulação forçada de ar, a $65^{\circ} \mathrm{C} \pm 2{ }^{\circ} \mathrm{C}$, até atingirem massa constante, e após, foram pesadas e moídas. Em seguida, o teor de N, obtido após a digestão sulfúrica, foi determinado em destilador de arraste de vapores do tipo semimicro Kjeldhal (Tedesco et al., 1995). O teor de Pe K foi determinado, após a digestão nitroperclórica, em espectrofotômetro e fotômetro de chama, respectivamente (EMBRAPA, 1999). Com os teores N, P e K determinou-se o acúmulo de cada nutriente, na parte aérea das plantas de cobertura, e calculou-se a relação $\mathrm{C} / \mathrm{N}$ do material, considerando que $40 \%$ da matéria seca é carbono orgânico, conforme proposto por Ceretta et al. (2002).

A colheita do trigo foi realizada, manualmente, no dia 08/09/2006, coletando-se todas as plantas contidas em uma área de 4,0 $\mathrm{m}^{2}$ (seis linhas de 4,0 m de comprimento). As características agronômicas do trigo foram avaliadas mediante as seguintes variáveis: altura de plantas, número de espigas por $\mathrm{m}^{2}$, número de grãos por espiga, massa de 1000 grãos e produtividade de grãos.

A semeadura do milho, híbrido simples PIONNER 30F80, de ciclo precoce, foi realizada mecanicamente em $14 / 10 / 2006$, sobre a resteva das culturas de inverno, utilizando-se uma densidade inicial 62.500 sementes ha-1 ${ }^{-1}$ sementes $\mathrm{m}^{-1}$ ). A emergência das plantas ocorreu em 20/ 10/2006 e, por ocasião da colheita, a densidade populacional final da cultura foi de $57.764 \pm 857$ plantas ha ${ }^{-1}$. Cada parcela experimental era constituída de oito linhas de milho, de $12 \mathrm{~m}$ de comprimento cada, com espaçamento entre linhas de $0,80 \mathrm{~m}$.

A adubação do milho foi composta de $120 \mathrm{~kg} \mathrm{ha}^{-1}$ de $\mathrm{N}, 52 \mathrm{~kg} \mathrm{ha}^{-1}$ de $\mathrm{P}_{2} \mathrm{O}_{5}$ e $30 \mathrm{~kg} \mathrm{ha}^{-1}$ de $\mathrm{K}_{2} \mathrm{O}$ (Raij et al., 1997). A adubação mineral foi realizada, aplicando-se na base de semeadura $188 \mathrm{~kg} \mathrm{ha}^{-1}$ da formulação 8-28-16 e $105 \mathrm{~kg} \mathrm{ha}^{-1}$ de $\mathrm{N}$ em cobertura, na forma de ureia, em duas aplicações de 50 e $55 \mathrm{~kg} \mathrm{ha}^{-1}$ de N, respectivamente, quan- 
do as plantas apresentavam-se com 4 e 8 folhas totalmente expandidas. A adubação orgânica e organomineral foi realizada com a aplicação de $38 \mathrm{~m}^{3}$ ha ${ }^{-1}$ de dejetos de suínos, conforme a necessidade do milho e análise do dejeto. $\mathrm{O}$ dejeto suíno apresentou as seguintes características físico-químicas: $3,7 \%$ de matéria seca; $3,15 \mathrm{~kg} \mathrm{~m}^{-3}$ de $\mathrm{N}$; $1,37 \mathrm{~kg} \mathrm{~m}^{-3} \mathrm{de}_{2} \mathrm{O}_{5} ; 0,78 \mathrm{~kg} \mathrm{~m}^{-3}$ de $\mathrm{K}_{2} \mathrm{O} ; 42,1 \mathrm{~kg} \mathrm{~m}^{-3}$ de Cae $2,7 \mathrm{~kg} \mathrm{~m}^{-3}$ de $\mathrm{Mg}$.

No florescimento do milho, foram efetuadas amostragens do tecido foliar para avaliar o estado nutricional das plantas. Coletou-se o terço médio com nervura da folha oposta e abaixo da inserção da espiga principal, num total de 10 folhas por unidade experimental, conforme procedimentos descritos por Malavolta et al. (1997). As folhas coletadas foram lavadas em água destilada e secas em estufa de circulação forçada de ar, a $65^{\circ} \mathrm{C} \pm 2{ }^{\circ} \mathrm{C}$, por $72 \mathrm{~h}$, e moídas em moinho tipo Wiley. $\mathrm{O}$ teor de $\mathrm{N}$ foi determinado pelo método Kjeldhal (Tedesco et al., 1995). Os teores de P, K, Ca e Mg foram determinados em espectrofotômetro e espectrômetro de absorção atômica, modalidade chama (EMBRAPA, 1999).

A colheita do milho foi realizada manualmente, no dia $28 / 02 / 2007$, coletando-se todas as espigas contidas em $8 \mathrm{~m}$ das quatro linhas centrais, totalizando $25,6 \mathrm{~m}^{2} \mathrm{de}$ área útil, em cada parcela. A produtividade de grãos foi obtida pela pesagem dos grãos oriundos das áreas úteis das parcelas experimentais ( $\mathrm{g}$ parcela $\left.{ }^{-1}\right)$, a qual foi convertida para $\mathrm{kg} \mathrm{ha}^{-1}$ e padronizada para $130 \mathrm{~g} \mathrm{~kg}^{-1}$ (base úmida.).

Os resultados obtidos foram submetidos à análise de variância, aplicando-se o teste $\mathrm{F}$ a 5\% de probabilidade. As médias foram comparadas pelo teste de Tukey, para adubações, e pelo teste F, para sistemas de culturas, ambos a $5 \%$ de probabilidade.

\section{RESULTADOS E DISCUSSÃO}

\section{Culturas de inverno}

A produção média de biomassa seca do consórcio de plantas de cobertura foi de $5.184 \mathrm{~kg} \mathrm{ha}^{-1}$ (Tabela 1), valor este dentro dos pré-estabelecidos por Calegari (2006), o qual demonstrou que a capacidade de produção de biomassa seca do consórcio entre aveia preta+ervilhaca peluda+nabo forrageiro varia de 4.000 a $9.000 \mathrm{~kg} \mathrm{ha}^{-1}$. Isso evidencia que a utilização de diferentes espécies de plantas de cobertura em consórcio é capaz de produzir quantidade adequada de biomassa, tornando-se importante para manutenção do sistema de semeadura direta. Giacomini et al. (2003) também evidenciaram o potencial de uso de sistemas consorciados de aveia, ervilhaca e nabo, para obtenção de níveis adequados de matéria seca como cobertura de solo no inverno, tendo obtido produtividades acima de $5.000 \mathrm{~kg} \mathrm{ha}^{-1}$ de matéria seca.
$\mathrm{O}$ acúmulo de $\mathrm{N}, \mathrm{P}$ e $\mathrm{K}$ na parte aérea das plantas de cobertura foi de 60,$6 ; 35,8$ e $95,9 \mathrm{~kg} \mathrm{ha}^{-1}$, respectivamente (Tabela 1). Calegari (2006) relatou que o acúmulo médio de $\mathrm{N}$ desse tipo de consórcio varia de 80 a $120 \mathrm{~kg} \mathrm{ha}^{-1}$. O menor acúmulo de $\mathrm{N}$ encontrado neste trabalho pode ser atribuído à predominância da aveia e do nabo no consórcio das plantas de cobertura, pois a ervilhaca peluda não encontrou condições ideais para o seu desenvolvimento, sendo suplantada, principalmente, pela aveia preta. Esse resultado foi atribuído à alta capacidade de competição da aveia, que dificulta o desenvolvimento de plantas de outras espécies em associação (Aita, 1997), confirmando as observações realizadas por Monegat (1991), de que a aveia é uma planta com maior rusticidade e agressividade do que a ervilhaca, além de apresentar como característica a capacidade de perfilhar.

Heinrichs et al. (2001), avaliando diferentes proporções de consórcio entre aveia e ervilhaca, verificaram que, quando a aveia representou apenas $10 \%$ na densidade de semeadura, contribuiu com mais da metade (52\%) da produção total de biomassa do consórcio. Neste estudo, a aveia preta representou $62,5 \%$ da densidade total de semeadura $\left(50 \mathrm{~kg} \mathrm{ha}^{-1}\right)$, ao passo que a ervilhaca peluda e o nabo forrageiro representaram, respectivamente, 25 e $12,5 \%$ da densidade de semeadura do consórcio (20 e $\left.10 \mathrm{~kg} \mathrm{ha}^{-1}\right)$. Portanto, a proporção de sementes utilizadas na semeadura das três espécies de cobertura de solo, em sistemas consorciado, não se mostrou adequada para as condições edafoclimáticas da região oeste do Paraná.

A relação $\mathrm{C} / \mathrm{N}$ do consórcio de plantas de cobertura foi de 34,2 (Tabela 1), valor intermediário em relação à $\mathrm{C} / \mathrm{N}$ obtida para os cultivos isolados de aveia e de nabo, que, em média, são de 42:1 e 18:1, respectivamente (Ranells \& Wagger, 1997). Tais resultados estão de acordo com aqueles, obtidos em diversos trabalhos, realizados em diferentes condições edafoclimáticas, por (Ranells \& Wagger, 1997; Heinrichs et al., 2001; Giacomini et al., 2003).

As fontes de nutrientes não influenciaram significativamente a maioria dos componentes de produção e produtividade de grãos do trigo (Tabela 2), evidenciando-se que a aplicação de $25 \mathrm{~m}^{3} \mathrm{ha}^{-1}$ de dejeto suíno (adubação orgânica) supriu plenamente a necessidade nutricional da cultura, uma vez que a produtividade de grãos foi semelhante à da adubação mineral recomendada para a cultura. Tais resultados corroboram os obtidos por Matsi et al. (2003), os quais verificaram que a produtividade de trigo, com a aplicação de $40 \mathrm{~m}^{3} \mathrm{ha}^{-1}$ de esterco líquido bovino, foi equivalente à da adubação mineral, nos quatro anos de avaliação. De modo similar, Pauletti et al. (2008) evidenciaram que a aplicação de $60 \mathrm{~m}^{3}$ ha-1 de dejeto bovino proporcionou produtividade de trigo semelhante à da adubação mineral recomendada. 


\section{Diagnose foliar e produtividade do milho}

Os resultados não evidenciaram efeitos significativos da interação entre os sistemas de culturas e as fontes de nutrientes, para os teores foliares de N, P e K e produtividade de milho. Porém, houve efeito dos sistemas de culturas sobre os teores de $\mathrm{N}$ e $\mathrm{K}$, no tecido foliar e sobre a produtividade de milho (Tabela 3 ). As fontes de nutrientes apenas influenciaram, significativamente, o teor de $\mathrm{N}$ e a produtividade de grãos de milho (Tabela 3 ).

Os maiores teores de $\mathrm{N}$ e de $\mathrm{K}$ no tecido foliar do milho foram obtidos no sistema após trigo (Tabela 3). O menor teor de N, obtido no cultivo de milho, em sucessão às plantas de cobertura, foi ocasionado pelo menor acúmulo de $\mathrm{N}$ na matéria seca das plantas de cobertura e da sua alta relação C/N (Tabela 1). De acordo com Cantarella (2007), a velocidade de disponibilização do N, proveniente dos restos vegetais de cultivos de cobertura, depende de vários fatores, dos quais os mais importantes são a quantidade de $\mathrm{N}$ acumulada na matéria seca e a relação $\mathrm{C} /$
N da palhada. Segundo Argenta et al. (2002), pelo fato de a biomassa das plantas de cobertura apresentar alta relação $\mathrm{C} / \mathrm{N}$, os micro-organismos retiram $\mathrm{N}$ do solo, provocando imobilização temporária. Isto diminui a disponibilidade de N para a cultura subseqüente do milho, corroborando os resultados obtidos por Bortolini et al. (2000), Aita et al. (2001) e Amado et al. (2003). Por outro lado, Mai et al. (2003) relatam que o consórcio de gramíneas, com leguminosas ou nabo forrageiro, pode ser utilizado para maior produção de matéria seca no inverno, por causa da maior oferta de $\mathrm{N}$ no início do desenvolvimento da cultura em sucessão, mediante maior equilíbrio da relação $\mathrm{C} / \mathrm{N}$ dos resíduos do consórcio.

Ressalta-se que em ambos os sistemas de culturas, os teores foliares de $\mathrm{N}$ e K do milho (Tabela 3) mostraram-se inferiores aos valores apresentados por Malavolta et al. (1997), que consideram, como teores adequados, de 28 a $35 \mathrm{~g} \mathrm{~kg}^{-1}$ para o $\mathrm{N}$ e de 13 a $30 \mathrm{~g} \mathrm{~kg}^{-1}$ para o $\mathrm{K}$, o que pode ser explicado como decorrência da alta preci-

Tabela 1. Produção de massa de matéria seca, acúmulo de N, Pe K e relação C/N na parte aérea do consórcio de plantas de cobertura

\begin{tabular}{|c|c|c|c|c|c|c|c|}
\hline \multicolumn{3}{|c|}{ Teor } & \multirow{2}{*}{$\begin{array}{c}\text { Matéria } \\
\text { seca }\end{array}$} & \multicolumn{3}{|c|}{ Acúmulo } & \multirow{2}{*}{$\begin{array}{c}\text { Relação } \\
\text { C/N } \mathbf{N}^{(1)}\end{array}$} \\
\hline $\mathbf{N}$ & $\mathbf{P}$ & $\mathbf{K}$ & & $\mathbf{N}$ & $\mathbf{P}$ & $\mathbf{K}$ & \\
\hline 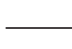 & $\mathrm{g} \mathrm{kg}^{-1}$ & 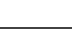 & - & 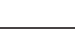 & 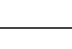 & & \\
\hline 11,7 & 6,9 & 18,5 & 5.184 & 60,6 & 35,8 & 95,9 & 34,2 \\
\hline
\end{tabular}

(1) Considerando que $40 \%$ da massa seca é carbono (Ceretta et al., 2002).

Tabela 2. Componentes de produção e produtividade de trigo, fertilizado com diferentes fontes de nutrientes

\begin{tabular}{lccccc}
\hline Adubação & $\begin{array}{c}\text { Altura de planta } \\
\mathbf{~ c m}\end{array}$ & $\begin{array}{c}\text { Espigas por } \mathbf{~ m}^{\mathbf{2}} \\
\mathbf{n}^{\mathbf{0}}\end{array}$ & $\begin{array}{c}\text { Grãos por espiga } \\
\mathbf{n}^{\mathbf{0}}\end{array}$ & $\begin{array}{c}\text { Massa de mil grãos } \\
\mathbf{g}\end{array}$ & $\begin{array}{c}\text { Produtividade } \\
\mathbf{k g ~ h a}^{-1}\end{array}$ \\
\hline Mineral & $56,9 \mathrm{a}$ & $425,1 \mathrm{a}$ & $15,1 \mathrm{~b}$ & $36,8 \mathrm{a}$ & $1.655 \mathrm{a}$ \\
Orgânica & $56,9 \mathrm{a}$ & $424,3 \mathrm{a}$ & $16,0 \mathrm{ab}$ & $37,6 \mathrm{a}$ & $1.599 \mathrm{a}$ \\
Organomineral & $59,2 \mathrm{a}$ & $430,2 \mathrm{a}$ & $17,6 \mathrm{a}$ & $33,9 \mathrm{a}$ & $1.684 \mathrm{a}$ \\
\hline $\mathrm{CV}(\%)$ & 2,32 & 10,45 & 6,67 & 8,99 & 11,50 \\
\hline
\end{tabular}

Média seguida da mesma letra, na coluna, não diferem estatisticamente entre si pelo teste de Tukey a 5\% de probabilidade.

Tabela 3. Teores dos macronutrientes no tecido foliar e produtividade de grãos de milho em diferentes sistemas de culturas e fonte de nutrientes

\begin{tabular}{lcccccc}
\hline Fonte de variação & $\mathbf{N}$ & $\mathbf{P}$ & $\mathbf{K}$ & $\mathbf{C a}$ & $\mathbf{M g}$ & Produtividade \\
\hline & \multicolumn{7}{c}{$\mathbf{g ~ k g}^{-1}$} & $\mathbf{k g ~ h a}^{-1}$ \\
\hline \multicolumn{7}{c}{ Sistema de culturas } \\
\hline Trigo/Milho & $22,2 \mathrm{~A}$ & $6,8 \mathrm{~A}$ & $11,7 \mathrm{~A}$ & $8,5 \mathrm{~A}$ & $3,5 \mathrm{~A}$ & $6.820 \mathrm{~A}$ \\
Pl.Cobertura/Milho & $20,6 \mathrm{~B}$ & $7,4 \mathrm{~A}$ & $10,4 \mathrm{~B}$ & $8,6 \mathrm{~A}$ & $3,5 \mathrm{~A}$ & $6.179 \mathrm{~B}$ \\
\hline \multicolumn{7}{c}{ Fonte de nutrientes } \\
\hline Mineral & $23,6 \mathrm{a}$ & $8,1 \mathrm{a}$ & $11,4 \mathrm{a}$ & $8,1 \mathrm{a}$ & $3,4 \mathrm{a}$ & $7.277 \mathrm{a}$ \\
Orgânica & $20,9 \mathrm{~b}$ & $6,9 \mathrm{a}$ & $11,1 \mathrm{a}$ & $8,8 \mathrm{a}$ & $3,6 \mathrm{a}$ & $6.336 \mathrm{~b}$ \\
Organomineral & $19,7 \mathrm{~b}$ & $6,2 \mathrm{a}$ & $10,8 \mathrm{a}$ & $8,7 \mathrm{a}$ & $3,5 \mathrm{a}$ & $5887 \mathrm{~b}$ \\
CV $(\%)$ & 5,92 & 20,35 & 12,72 & 9,77 & 9,11 & 12,62
\end{tabular}

Letras maiúsculas diferentes para sistemas de culturas e minúsculas para fonte de nutrientes, diferem entre si pelo teste F e de Tukey, respectivamente, a $5 \%$ de probabilidade. 
pitação pluviométrica, ocorrida no período de primavera/verão (Figura 1), a qual deve ter promovido à lixiviação de $\mathrm{N}$ e do K no perfil do solo. Dentre os nutrientes, o N (Boeira, 2009; Fey et al., 2010) e o K (Rosolem et al., 2006; Werle et al., 2008) são os que apresentam maior mobilidade no perfil em solos bem drenados. Segundo Klepker \& Anghinoni (1996), a mobilidade dos nutrientes no perfil é um dos principais fatores que podem afetar a sua disponibilidade para as plantas.

O teor de P obtido no tecido foliar do milho (Tabela 3 ) foi superior aos teores considerados adequados (2,5 a 4,5 $\mathrm{g} \mathrm{kg}^{-1}$ ), estabelecidos por Malavolta et al. (1997), resultados estes devidos à alta disponibilidade de $\mathrm{P}$ no solo (21,8 $\mathrm{mg} \mathrm{dm}^{-3}$ extraído por Melhich 1), evidenciada na análise do solo antes da implantação do experimento. Outro fato pode ser em decorrência da maior difusão deste nutriente, verificada no sistema de plantio direto. Segundo Muzilli (1983), a maior disponibilidade de P para as plantas no sistema de semeadura direta deve-se ao maior teor de umidade existente no solo, o qual favorece a taxa de difusão do $\mathrm{P}$ até as raízes.

A produtividade de milho foi alterada pelos sistemas de culturas e fontes de nutrientes (Tabela 3). A maior produtividade de grãos foi obtida quando o milho foi cultivado em sucessão ao trigo, com incrementos na ordem de $641 \mathrm{~kg} \mathrm{ha}^{-1}$ de grãos (10\%), em comparação com o cultivo de milho em sucessão às plantas de cobertura. Este resultado pode ser explicado como decorrência da relação $\mathrm{C} / \mathrm{N}$ das plantas de cobertura (Tabela 1), que ocasionou a imobilização, ao menos temporária, do $\mathrm{N}$ no sistema, e, consequentemente, redução na produtividade. A relação $\mathrm{C} / \mathrm{N}$ tem sido a característica mais usada em modelos para prever a disponibilidade de $\mathrm{N}$ no solo, durante a decomposição de materiais orgânicos (Nicolardot et al., 2001). Para Allison (1966), resíduos vegetais com valores de C/N entre 25 e 30 apresentam equilíbrio entre os processos de mineralização e imobilização. Usando-se esses valores como base, pode-se inferir que a imobilização deverá superar a mineralização, resultando em aumento da disponibilidade de $\mathrm{N}$ no solo, durante a decomposição dos resíduos culturais.

Resultados semelhantes foram obtidos por Aita et al. (2001), os quais, avaliando diferentes plantas de cobertura do solo no inverno, verificaram menor produtividade do milho em sucessão a aveia preta, quando comparada com a sucessão às leguminosa ervilhaca comum, ervilha forrageira, chícharo e tremoço azul. Isto, segundo os autores, ocorreu por causa da maior imobilização do $\mathrm{N}$ pela aveia preta, decorrente da alta relação $\mathrm{C} / \mathrm{N}$ do material vegetal deixado na superfície do solo. Amado et al. (2003) constataram que a liberação de $\mathrm{N}$ pela aveia preta foi inversamente relacionada com a relação $\mathrm{C} / \mathrm{N}$ dos resíduos. Assim, no planejamento das espécies a serem utilizadas no sistema de culturas, deve-se dar preferência a espécies leguminosas, quando se pretende implantar a cultura do milho no verão. Aita et al. (2006) trabalharam com milho em sucessão a aveia solteira e em sucessão a aveia+ervilhaca. No cultivo de milho em sucessão a aveia+ervilhaca houve economia de $50 \%$ na quantidade de dejetos de suínos necessária para atingir a máxima produtividade de grãos do milho, indicando a interferência da leguminosa na produção de milho. Corroborando a afirmação de Bortolini et al. (2000) de que a introdução de ervilhaca em consórcio com aveia diminui a necessidade de adubação nitrogenada, para o cultivo do milho em sucessão.

As fontes de nutrientes influenciaram, significativamente, o teor foliar de $\mathrm{N}$ e a produtividade de milho (Tabela 3). $\mathrm{O}$ maior teor de $\mathrm{N}$ e produtividade de milho foram obtidos quando se utilizou a adubação mineral. Tais resultados são devidos à diferente solubilidade das fontes utilizadas, a fonte mineral possui alta solubilidade e o dejeto suíno, utilizado na adubação orgânica e organomineral, apresenta menor disponibilidade imediata e depende da mineralização para liberar os nutrientes, principalmente N e P. De acordo com Selbach \& Sá (2004), em torno de $70 \%$ do $\mathrm{N}$ e $80 \%$ do $\mathrm{P}$ contidos nos dejetos de suíno são liberados no primeiro cultivo. Quando os dejetos são aplicados no solo, o $\mathrm{N}$ amoniacal é oxidado até nitrato, pelas bactérias nitrificadoras. Isto porque a proporção do $\mathrm{N}$ total que se encontra na forma de $\mathrm{N}-\mathrm{NH}_{4}{ }^{+}+\mathrm{N}-\mathrm{NH}_{3}$ pode chegar a 70\%, quando os dejetos forem armazenados em esterqueiras anaeróbias (Scherer et al., 1996).

Outro fator que pode ter proporcionado este menor teor de $\mathrm{N}$ e menor produtividade de milho foi a lixiviação do $\mathrm{N}$ no perfil do solo. Pois, como a aplicação dos dejetos foi realizada antes da semeadura da cultura, a rápida nitrificação do $\mathrm{N}$ amoniacal dos dejetos poderá resultar em teores elevados de $\mathrm{N}_{-} \mathrm{NO}_{3}{ }^{-}$no solo, em um momento em que a demanda de $\mathrm{N}$ das plantas de milho ainda é pequena (Aita $e t$ al., 2006). Assim, a elevada precipitação pluviométrica ocorrida (Figura 1) resultou em perdas de $\mathrm{N}$ por lixiviação de N$\mathrm{NO}_{3}{ }^{-}$e desnitrificação, uma vez que, em condições anaeróbias, o $\mathrm{N}_{-} \mathrm{NO}_{3}^{-}$atua como aceptor de elétrons da cadeia respiratória de algumas bactérias, sendo reduzido à forma gasosa de $\mathrm{N}_{2}$ (Dendooven et al., 1998). Segundo Aita et al. (2006), esses dois processos podem resultar na diminuição do potencial fertilizante nitrogenado dos dejetos e no aumento no seu potencial poluidor do ambiente.

Trabalhando em Argissolo Vermelho-Amarelo de Minas Gerais, Gomes et al. (2005) também verificaram que a associação de composto orgânico e adubo químico não influenciou, significativamente, o rendimento da cultura de milho. Entretanto, os mesmos autores relataram que a aplicação de $40 \mathrm{~m}^{3} \mathrm{ha}^{-1}$ de composto orgânico resultou em uma produção semelhante à da dose de $500 \mathrm{~kg} \mathrm{ha}^{-1}$ da formulação 04-14-08. 


\section{CONCLUSÕES}

O cultivo de milho em sucessão ao trigo proporciona a maior absorção de $\mathrm{N}$ e K e maior produtividade da cultura.

A adubação mineral proporciona maiores absorção de $\mathrm{N}$ e produtividade de milho, em comparação com as adubações orgânica e organomineral com dejetos de suínos.

\section{REFERÊNCIAS}

Aita C (1997) Dinâmica do nitrogênio no solo durante a decomposição de plantas de cobertura: efeito sobre a disponibilidade de nitrogênio para a cultura em sucessão. In: Fries MR \& Dalmolin RSD (Eds.). Atualização em recomendação de adubação e calagem: ênfase em plantio direto. Santa Maria, UFSM, p.76-111.

Aita C, Basso CJ, Ceretta CA, Gonçalves CN \& Da Ros COC (2001) Plantas de cobertura de solo como fontes de nitrogênio ao milho. Revista Brasileira de Ciência do Solo, 25:157-1165.

Aita C, Port O \& Giacomini SJ (2006) Dinâmica do nitrogênio no solo e produção de fitomassa por plantas de cobertura no outono/inverno com o uso de dejetos de suínos. Revista Brasileira de Ciência do Solo, 30:901-910.

Allison FE (1966) The fate of nitrogen applied to soils. Advances in Agronomy, 18:219-258.

Amado TJC, Santi A \& Acosta JAA (2003) Adubação nitrogenada na aveia preta. II - Influência na decomposição de resíduos, liberação de nitrogênio e rendimento de milho sob sistema plantio direto. Revista Brasileira de Ciência do Solo, 27:1085-1096.

Argenta G, Silva PRF, Mielniczuk J \& Bortolini CG (2002) Parâmetros de planta como indicadores do nível de nitrogênio na cultura do milho. Pesquisa Agropecuária Brasileira, 37:519-527.

Boeira RC (2009) Lixiviação de nitrogênio em latossolo incubado com lodo de esgoto. Revista Brasileira de Ciência do Solo, $33: 947-958$

Bortolini CG, Silva PRF \& Argenta G (2000) Sistemas consorciados de aveia preta e ervilhaca comum como cobertura de solo e seus efeitos na cultura do milho em sucessão. Revista Brasileira de Ciência do Solo, 24:897-903.

Calegari A (2006) Plantas de cobertura. In: Casão Júnior R, Siqueira R, Mehta YR \& Pasini JJ (Eds.). Sistema plantio direto com qualidade. Londrina, IAPAR; Foz do Iguaçu, ITAIPU Binacional. p. $55-73$.

Cantarella H (2007) Nitrogênio. In: Novais RF, Alvarez V VH, Barros NF, Fontes RL, Cantarutti RB \& Neves JCL (Eds.). Fertilidade do solo. Viçosa, SBCS. p.375-470.

Ceretta CA, Basso CJ, Herbes MG, Poletto N \& Silveira MJ (2002) Produção e decomposição de fitomassa de plantas invernais de cobertura de solo e milho, sob diferentes manejos da adubação nitrogenada. Ciência Rural, 32:49-54.

Dendooven E, Bonhomme R, Merckx K \& Vlassak A (1998) N dynamics and $\mathrm{N}_{2} \mathrm{O}$ production following pig slurry application to a loamy soil. Biology and Fertility of Soils, 26:224-228.

EMBRAPA - Centro Nacional de Pesquisa de Solos (1999) Manual de análises químicas de solos, plantas e fertilizantes. Brasília, CNPS. 370p.

EMBRAPA - Centro Nacional de Pesquisa de Solos (2006) Sistema brasileiro de classificação de solos. $2^{\mathrm{a}}$ ed. Brasília, EMBRAPA/ DPI. 306p.

Fey R, Zoz T, Steiner F, Richart A \& Brito OR (2010) Leaching of nitrogen in column in regarding soil particle size. Scientia Agraria, 11:181-185.
Giacomini SJ, Aita C, Vendruscolo ERO, Cubilla M, Nicoloso RS \& Fries MR (2003) Matéria seca, relação C/N e acúmulo de nitrogênio, fósforo e potássio em misturas de plantas de cobertura de solo. Revista Brasileira de Ciência do Solo, 27:325-334.

Gomes JA, Scapim CA, Braccini AL, Vidigal Filho OS, Sagrilo E \& Mora F (2005) Adubações orgânica e mineral, produtividade do milho e características físicas e químicas de um Argissolo Vermelho Vermelho-Amarelo. Acta Scientiarum Agronomy, 27:521-529.

Heinrichs R, Aita C, Amado TJC \& Fancelli AL (2001) Cultivo consorciado de aveia e ervilhaca: relação $\mathrm{C} / \mathrm{N}$ da fitomassa e produtividade do milho em sucessão. Revista Brasileira de Ciência do Solo, 25:331-340.

Klepker D \& Anghinoni I (1996) Modos de adubação, absorção de nutrientes e rendimento de milho em diferentes preparos de solo. Pesquisa Agropecuária Gaúcha, 2:79-86.

Mai MEM, Ceretta CA, Basso CJ, Silveira MJ, Pavinato A \& Pavinato OS (2003) Manejo da adubação nitrogenada na sucessão aveia-preta/milho no sistema plantio direto. Pesquisa Agropecuária Brasileira, 38:125-131.

Malavolta E, Vitti GC \& Oliveira AS (1997) Avaliação do estado nutricional das plantas: princípios e aplicações. Piracicaba, Potafós. 319p.

Matsi T, Lithourgidis AS \& Gagianas AA (2003) Effects of injected liquid cattle manure on growth and yield of winter wheat and soil characteristics. Agronomy Journal, 95:592-596.

Monegat C (1991) Plantas de cobertura do solo: características e manejo em pequenas propriedades. Chapecó, Ed. do Autor. 337p.

Muzilli O (1983) Influência do sistema de plantio direto comparado ao convencional sobre a fertilidade da camada arável do solo. Revista Brasileira de Ciência do Solo, 7:95-102.

Nicolardot B, Recous S \& Mary B (2001) Simulation of C and N mineralisation during crop residue decomposition: A simple dynamic model based on the $\mathrm{C} / \mathrm{N}$ ratio of the residues. Plant and Soil, 228:83-103

Pauletti V, Barcellos M, Motta ACV, Serrat BM \& Santos IR (2008) Produtividade de culturas sob diferentes doses de esterco líquido de gado de leite e de adubo mineral. Scientia Agraria, 9:199-205.

Ranells NN \& Wagger MG (1997) Nitrogen-15 recovery and release by rye and crimson clover cover crops. Agronomy Journal, 61:943-948.

Raij BV, Cantarella H, Quaggio JA \& Furlani AMC (1997) Recomendação de adubação e calagem para o estado de São Paulo. $2^{a}$ ed. Campinas, IAC. 285p. (Boletim Técnico, 100).

Rosolem CA, Santos FP, Foloni JSS \& Calonego JC (2006) Potássio no solo em conseqüência da adubação sobre a palha de milheto e chuva simulada. Pesquisa Agropecuária Brasileira, 41:1033-1040.

Selbach PA \& Sá ELS (2004) Fertilizantes orgânicos, organominerais e agricultura orgânica. In: Bissani CA, Gainello C, Tedesco MJ \& Camargo FAO (Eds.). Fertilidade dos solos e manejo da adubação de culturas. Porto Alegre, Gênesis, p.175186.

Scherer EE, Aita C \& Baldissera IT (1996) Avaliação da qualidade do esterco líquido de suínos da região Oeste Catarinense para fins de utilização como fertilizante. Florianópolis, EPAGRI, 46p. (Boletim Técnico, 79).

Tedesco MJ, Gianello C, Bissani CA, Bohnen H \& Volkweiss SJ (1995) Análises de solos, plantas e outros materiais. 2a ed. Porto Alegre, UFRGS, Departamento de Solos. 174p. (Boletim Técnico, 5).

Werle R, Garcia RA \& Rosolem CA (2008) Lixiviação de potássio em função da textura e da disponibilidade do nutriente no solo. Revista Brasileira de Ciência do Solo, 32:2297-2305. 